\title{
A focused review on materials and generations of coronary stents
}

\begin{abstract}
Lifestyle, aging, hypertension and genetic defects have been known to cause cardiovascular disease which continues to be the leading cause of mortality. Treatment of Cardiovascular disease like coronary artery disease has significant innovation, such as development of stents that overcomes some limitations of balloon angioplasty. In surgical procedure the surgeon must decide appropriate stent based on vessel features. Coronary stenting must represent the standard of care in order to decrease risk of adverse effect. This article studies the different diagnostic procedure such as angiography, angioplasty, implementation of stents and bypass, and different generation and features of stents.
\end{abstract}

Volume 4 Issue 3 - 2018

\author{
Hamidreza Shirzadfar, Farnoosh Vahid, \\ Farzane Kiafar, Sara Aledavood
}

Department of Biomedical Engineering, Sheikhbahaee University, Iran

Correspondence: Hamidreza Shirzadfar, Department of Biomedical Engineering, Sheikhbahaee University, Esfahan, Iran, Email h.shirzadfar@shbu.ac.ir,h.shirzadfar@gmail.com
Abbreviations: BMS, bare-metal stents; DES, drug eluting stents; PLLA, poly-L-lactic acid; ZES, zotarolimus-eluting stent; EES, everolimus-eluting stent; SES, sirolimus-eluting stent; PAD, peripheral artery disease; $\mathrm{PCI}$, percutaneous coronary intervention

\section{Introduction}

Blood vessels are tubular network which their duty is to supply organs by oxygen, water, nutrient and hormones and run all through body. ${ }^{1,2}$ All blood vessels consist of three separate layer:

\section{Tunica intima (Tunica internal)}

The tunica intima is the inner and the thinnest layer which is lining with simple squamous epithelium (endothelium). Boundary between blood in lumen (hallow in blood vessels) and walls of vessels is Endothelium. ${ }^{3}$ Damaging endothelium and exposure of blood to collagenous beneath leads clots to form. The intima has a key role in regulating capillary exchange and altering blood flow which by releasing endothelins constricts the smooth muscle in order to increase blood pressure. Overproduction of endothelins in most cases contributes cardiovascular disease. ${ }^{4}$ The endothelium is surrounded by basement membrane (basal lamina). This membrane is flexible, permeable and providing strength. In larger arteries the tunica layer is surrounded by a thin membrane distinct layer of elastic fibers, which is at the boundary with the tunica media, which is called internal elastic membrane (or the internal elastic lamina)

\section{Tunica adventitia}

Tunica adventitia (also called the tunica externa) is the outer and the thickest layer in veins. This layer is a substantial sheath consists of connective tissue composed of type I collagen fibers, elastin and nerves that supply the vessel. The tunica externa holds the vessel in place and is thick in order to prevent collapse of the blood vessel and provide protection from damage result in disruption of blood flow. ${ }^{5}$

One of the common disorders of the arteries is Atherosclerosis. That is a disease in which cholesterol, fat, calcium, cellular waste and other substances found in the blood build up plaques at the injury site and make artery narrow. Atherosclerosis starts when bad cholesterol (LDL) crosses the endothelium which becomes damaged and builds up in injured artery walls. The body to stream in to digest the LDL sends a type of white blood cell, but over years, the cells become plaque and get stuck at the affected site. In comparison to plaqued arteries, Healthy arteries have smooth inner walls, because the endothelium works to keep the inside of arteries smooth, and blood can easily pass through them. Genetic factors, high blood pressure, physical inactivity, smoking, or high amount of cholesterol and sugar in the blood can increase risk for Atherosclerosis. Atherosclerosis can affect any artery in the body, including particularly coronaries, carotids and peripheral arteries. Depending on which arteries are affected, Atherosclerosis can lead to serious problems blood clots can cause a heart attack, ${ }^{6,7}$ stroke, or even death. This process gradually continues to cause more inflammation by making more atheroma accumulates, which results in a bigger plaque. Eventually, the most dangerous outcome of atherosclerosis occurs when an area of plaque ruptures (breaks down). ${ }^{89}$ Then blood cell fragments (platelets) stick to the site of the injury and the blood flowing over the top of the plaque can clot because of clumping of platelets together, causing a blockage in the artery that limiting the flow of blood and result in a heart attack or stroke.

For treatment of atherosclerosis changing life style plays key role but in some cases whenever medical procedure were disable in healing, aggressive treatment is solution. The improvement in technology has given opportunity to access different therapies such as Angioplasty and stent placement, Endarterectomy (removing plaques), Fibrinolytic therapy ${ }^{10}$ Bypass surgery.

\section{Treatments for coronary heart and circulatory disease}

\section{Angiography}

Angiography is the test that uses x-ray and special dyes (contrast) to take pictures ${ }^{11}$ of the blood vessels anywhere of the body, including:
a. The arteries supplying the heart muscle
b. The arteries going to the brain
c. The arteries supplying the arms and legs
d. The arteries supplying the kidneys 


\section{e. All of the vessels coming from and going to the lungs}

The obtained pictures are called Angiograms. Angiograms are used to diagnose narrowing or blocking in vessels, in addition Angiograms can be used to find where that aneurysm happened.

\section{Procedure}

Doctor will place a small tube in a main blood vessel, ${ }^{12}$ which provides the ability of placing various catheters into the selected vessels and inject dye. After dye injection pictures are taken by $\mathrm{x}$-ray radiation, ${ }^{13}$ catheter usage provides the feasibility of combine treatment and diagnosis.

The important risks of angiography are:

a. Low risk of cancer due extreme exposure

b. Allergic reaction to x-ray material

c. Skin damage from dye leaks out

d. Low risk of clotting around of catheter ${ }^{14}$

e. It is dangerous for people with diabetes or kidney disease $\mathrm{e}^{15}$

The benefits of angiography are included in below:

a. Producing lucid and accurate pictures

b. Ability of showing blockages in arteries

\section{Angioplasty}

An angioplasty is a surgical procedure to open the blood vessels that provide blood to heart muscle. This surgery done after a heart attack. ${ }^{16}$ This procedure is also called percutaneous coronary intervention or PCI. Using stent in this procedure helps to keep the blood flowing and the artery from narrowing again.

At first, they make an incision in arm or groin. Then they insert a catheter with a tiny inflatable balloon on the end into your artery. Then doctor guide the catheter up through body to coronary arteries. Using X-ray ${ }^{17,18}$ that called fluoroscopy, ${ }^{19,20}$ video, and special dyes helps doctor to guide the catheter up into the blocked coronary artery. In the next step doctor pass a small wire through the catheter and then the next catheter that has a small balloon attached to it.

The fatty deposits, or plaque, get pushed against the wall of the artery. This work clears the way for blood flow. In some cases, the catheter is a stent. When the balloon is out, doctor removes the catheter.

Angioplasty can also relieve the symptoms of heart disease if you haven't had a heart attack. The risks of this procedure are bleeding, clotting, or bruising at the point of insertion, scar tissue or blood clots forming in the stent, an irregular heartbeat or arrhythmia, damage to a blood vessel, heart valve, or artery, a heart attack, kidney damage, especially in people who have preexisting kidney problems. ${ }^{21}$

\section{Stent}

Jacques Puel did the first stent implantation in 1986, and research about this subject took off immediately and developed. Since then, there have been significant developments in stents technology.

A stent is a latticed, metal scaffold inserted during percutaneous coronary intervention (PCI) and usually is placed in the treated portion of the vessel. The stents help to keep the vessel open ${ }^{22}$ and support the inner wall of artery. It also can decrease the odds of restenosis (becoming narrow or block again). ${ }^{23} \mathrm{~A}$ stent also can be useful to support an artery that was damaged or torn during PCI procedure. ${ }^{24}$

Stents help to the blocked arteries stay open after PCI. This allows blood to flow freely throughout arteries. Depending on where stent is placed, it can restore the flow of blood or other fluids. ${ }^{25}$

While PCI the surgeon will create a small incision in blood vessel in arm, groin, or neck. Then they will thread a flexible tube (catheter) with a balloon and stent on the end, to the clogged or narrow artery. ${ }^{26}$

They will inject special dyes into patient's body. The dyes will make it easier to guide the catheter through blood vessel to the clogged or narrow area in the artery. The Figure 1 demonstrates when they reach the eligible portion, they will inflate the balloon (using water pressure), to compress the plaque against the artery's wall. This will extend the stent and stretch artery, letting for increased blood flow. At the end, the doctor will deflate the balloon, take the catheter, and leave the stent in the absence.

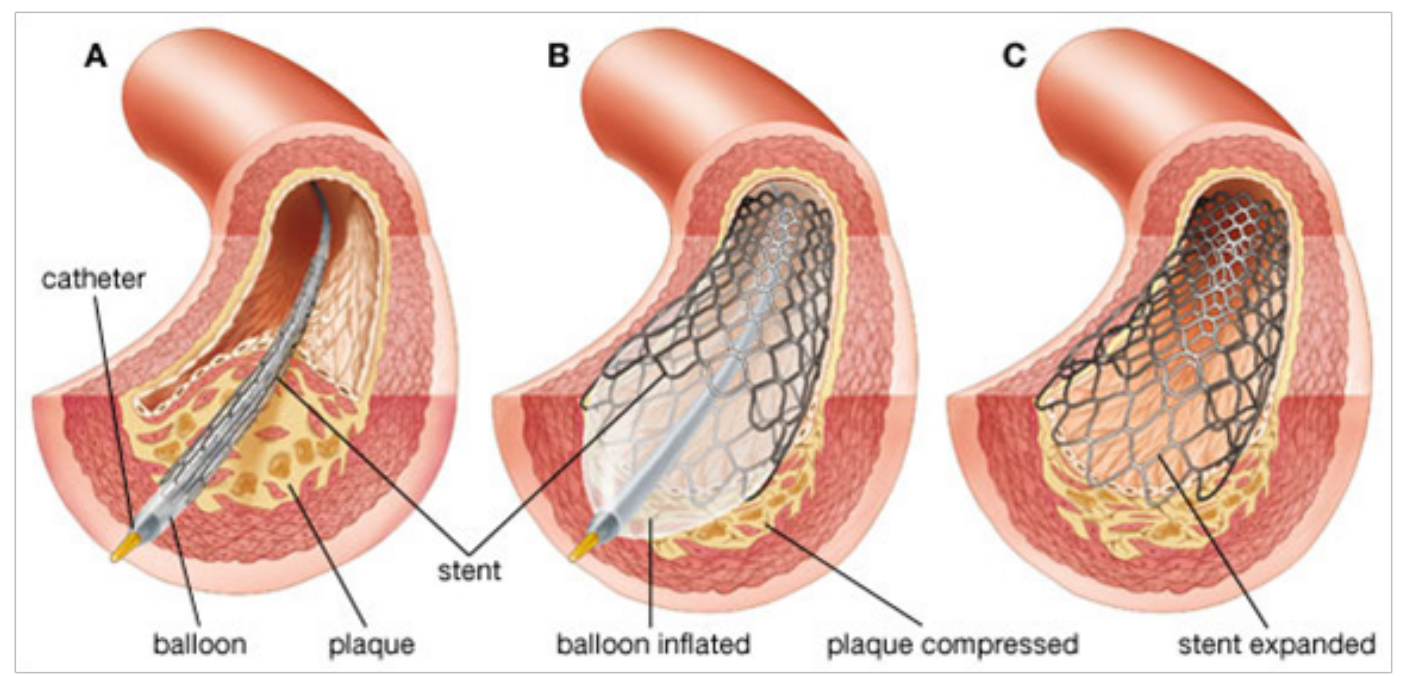

Figure I Stent implant procedure. (A) Stent insertion; (B) Stent expansion; (C) Stent remain in coronary artery. ${ }^{28}$ 
During this procedure, plaque and blood clots mustn't come loose and flout freely in bloodstream so a filter needed. Following the procedure, patient will need to take drugs to prevent creating clot within the stent. During the time, patient's own tissue will merge with the lattice of the stent, making artery stronger. ${ }^{27}$

\section{Stents can use for following items}

\section{Carotid arteries}

The carotid arteries supply oxygen rich blood to brain, thus the build up of plaque in them limits blood flow to brain and puts person at risk for a stroke.

\section{Other arteries}

Plaques also can build up in other arteries and narrow them, such as kidneys and limbs. Narrow kidney arteries can cause severe high blood pressure.

Narrow arteries in the limbs can cause peripheral artery disease (P.A.D), which can motive pain and cramping in affected leg or arm.

\section{Aorta in the chest or abdomen}

The aorta is a main artery that carries oxygen-rich blood from heart to the body. This artery passes over chest and down into the abdomen. During the time, walls of aorta can weaken in some areas which can motive swelling in the artery (aneurysm). An aneurysm in the aorta can burst, causing to fatal internal bleeding.

To help eschew a burst, doctor may use a fabric stent in the weak zone of the abdominal aorta. The stent provides a stronger internal lining for the artery.

\section{To seal aortic tears}

Existence a tear in inner wall of aorta is another problem that can happens. The tear can decrease blood flow to the tissue that is supplied by aorta. During the time, the tear can burst or shut off blood flow through the artery, which generally happens in the chest portion.

\section{Bypass surgery}

When some arteries that carry blood to heart muscle damage doctors use coronary artery bypass surgery or Heart bypass surgery. Surgeons use blood vessels taken from another area of body to replace the damaged arteries and repaired them as shown in Figure 2. These auxiliary arteries serve heart with oxygenated blood. If these arteries are blocked, the heart doesn't work normally and the cause of it is heart failure.

There are different types of heart bypass surgery. If only one artery is blocked the type of this bypass is Single bypass and when two arteries are blocked it called double bypass and when three arteries are blocked it is triple bypass and when four arteries are blocked is called quadruple bypass. A risk of having a heart attack depends on the number of damaged arteries. When plaque that is a material in blood, builds walls on arterial leads to less blood flows to the heart muscle. ${ }^{29,30}$

The muscle fail if do not receive enough blood to it. When arteries are so narrowed doctor suggested heart bypass surgery. There are some risks if any open-heart surgery done beforehand. Before heart bypass surgery, patients used some medications such as Beta-blockers, Cholesterol-reducing drugs.

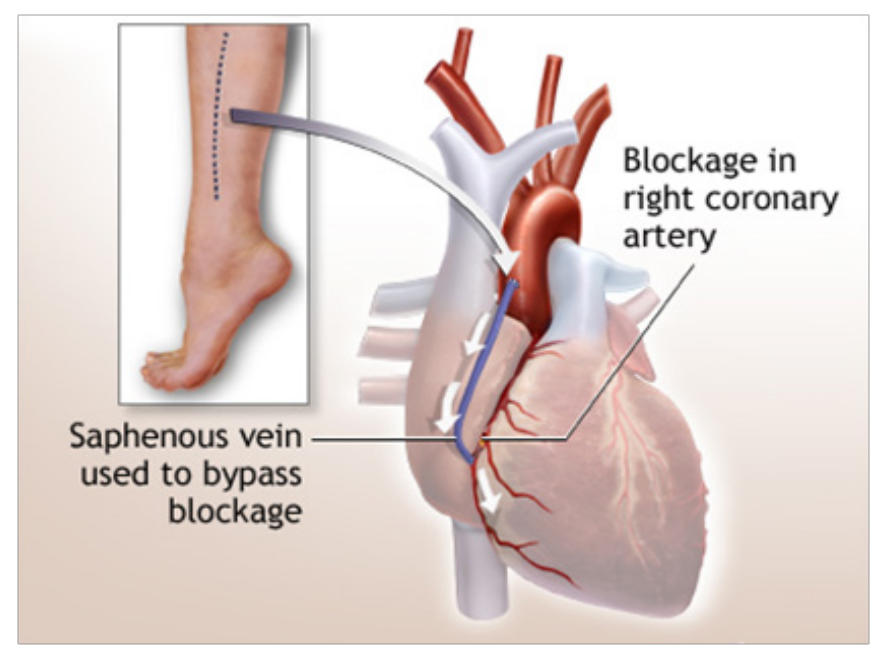

Figure 2 Replacing the damaged arteries. ${ }^{31}$

The surgery starts by making a small cut in the middle of chest and then rib cage spread and heart become visible. A cardiopulmonary bypass machine is used in this surgery to circulate oxygenated blood through body during the operation. ${ }^{32}$ For removing carbon dioxide used a machine that is pumped blood out of heat and then the machine is filled with oxygen. The oxygenated blood is pumped back into body without going through the heart and lungs. In some procedures using a heart-lung machine isn't necessary in this surgery also use extreme cooling for bring the temperature of body down. Surgeon then replace the healthy blood vessel from inside chest of patient wall or leg with damaged artery. So a bypass can fix a blocked artery.

After a successful heart bypass surgery shortness of breath, chest tightness, and high blood pressure will likely improve.

\section{Evolution of coronary stents}

Stenting is less invasive than bypass surgery and may eliminate need for bypass surgery. Due to its less invasive procedure the recovery is short. ${ }^{33}$

\section{Material}

The material used for stents have diversified since 1987, were introduced the first device which used stainless steel. This device was balloon expandable stents and the aim was to provide mechanical support, preventing acute occlusion and limiting vessel recoil. Although stents have progress in aspect of design and coatings, which cause re-intervention rats and low failure, but facing with stent thrombosis remains. Stent thrombosis mostly associated with type DES stents. ${ }^{34}$

Suitable stent must have following figures: biocompatible, flexible and capable of expansion. Incompatible implants in human body cause the immune system response, inflammation, trauma and scars. Inflammation which induced by Incompatible implants are chronic inflammation and cytotoxic chemical buildup. For example, Cobaltchromium which is used for Bare Metal Stent has some benefits in comparison to those stents which made of stainless steel, such as strength and therefore reducing strut profiles. ${ }^{35}$

New platinum-chromium alloy is a material used in special stent 
in order to improve balance of radiopacity and strength, for designing thinner strut.

Stents are needed for limited duration and they are unnecessary beyond the initial period of healing. Due to local stiffening of the vessel in long term some effects such as inflammatory response reduces. So the concept of biodegradable stents is noticed. ${ }^{36}$ Special stent which was fully bioresorbable to be implanted in humans was made of poly-L-lactic acid (PLLA).

In comparison to biodegradable polymer stents, Metallic biodegradable (for example magnesium alloy WE43) ${ }^{37}$ offer reducing recoil and increasing strength. ${ }^{38}$

\section{Generation}

Classification of stents is in three categories, first generation is bare-metal stents (BMS), second and third generation are drug eluting stents (DES). The Figure 3A presents the BMS and Figure 3B demonstrates the DES stents types. Innovation in stents, is because to overcome limitation of prior generation, includes biodegradable polymer stents, DES without a polymer and bioabsorbable scaffolds. Third generation stents have proven to have superior outcome in comparison to first and second generation. ${ }^{39}$
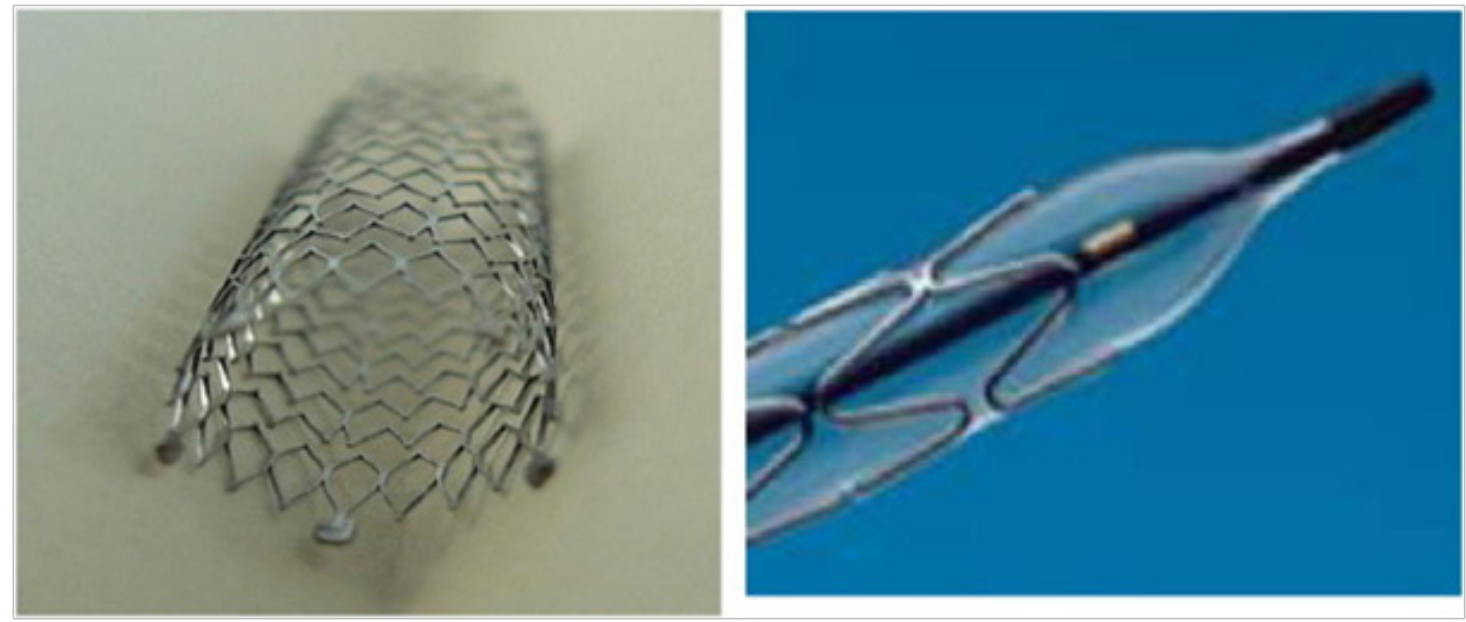

(A) The schematic of BMS.

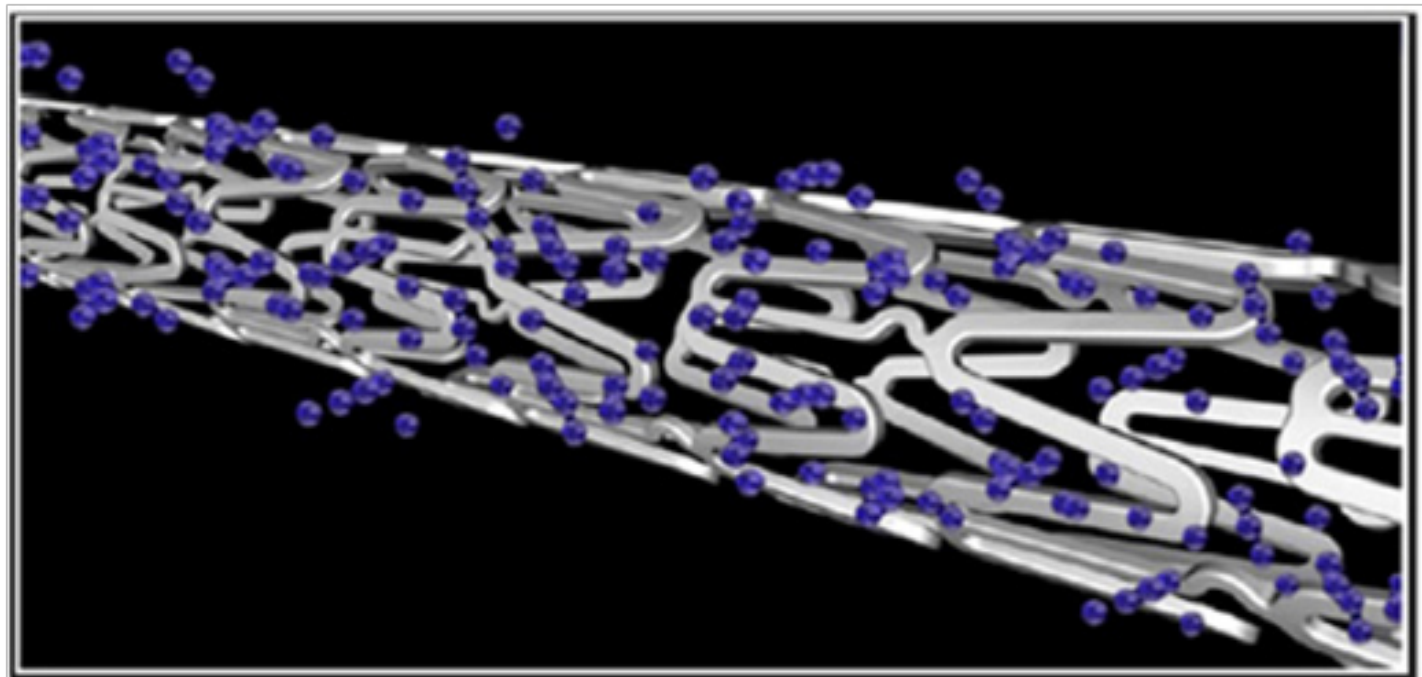

(B) The DES type

Figure 3 Different generation of stents. ${ }^{40}$

\section{Bare metal stents}

This kind of stent is mesh tube without coating drug, designed as vascular scaffold to reduce vascular recoil and vessel occlusions. Early Bare metal stents fabricated by different design (multicellular corrugated, serpentine and coil) and materials such as Nitinol wire coil (55\% nickel and 45\% titanium) and 316L stainless steel and cobalt chromium. The figures of stent must consist flexibility in order to conform the shape of arterial wall and hold the inner wall in it is newly position in terms of not changing diameter (ranging from $2 \mathrm{~mm}$ to $4 \mathrm{~mm}$, it depends on the vessel and type of disease) of an artery. ${ }^{41}$ In implant procedure, visualizing the position of stent by using fluoroscope is necessary, for this reason stent material must 
be radiopaque. Cobalt chromium stent material is more radiopaque in comparison to stainless steel one of benefits of Bare metal stents is decreasing the elastic recoil effect after balloon angioplasty surgery. ${ }^{42,43}$

All DES type stents have the same general components, their difference is in drug type, polymer and stent platform. DES can differ in aspect of deliverability, safety and efficacy.

\section{First generation DES}

First generation DES, sirolimus-eluting stent (SES), approved in 2003. Second generation DES, paclitaxel-eluting stent (PES), received FDA approval in $2004 .{ }^{44}$ These two generation were based on a combination of a durable biocompatible polymer, a metallic (316L stainless steel) platform and an antiproliferative drug. Because of superiority of second generation stents, the first generation is infrequently used. First-generation DES is sprayed BMS with drug and polymer. ${ }^{45}$

\section{Second generation DES}

Second generation DES, a zotarolimus-eluting stent (ZES) and an everolimus-eluting stent (EES), approved in 2008. ZES has further modification such as changing polymer which constructed from cobalt-chromium. Struts of this type of stent in thinner in comparison to previous generation that cause decreasing in neointimal response and more rapid re-endothelialisation. ${ }^{45,46}$

\section{Risks of using stent}

The use of stents also has a several risks such as:

a. Allergic reaction to drugs and dye used

b. Breathing problems caused by anesthesia

c. Artery occlusion: collagen sedimentation in blood vessels can cause artery occlusion after stent placed.

d. Blood clots: About 1-2 percent of people who have stented arteries develop a blood clot at the stent site. Blood clots can cause a heart attack, stroke, or other serious problems. The risk of blood clots is greatest during the first few months after the stent is placed in the artery. Take aspirin and another anticlotting medicine, such as clopidogrel, for at least 1 month or up to a year or more after having a stent procedure. These medicines help prevent blood clots. ${ }^{47}$

e. Infection of the veins: infection can occur after any invasive action.

f. Kidney stone caused by bladder stent use: materials that used in angioplasty and stenting can cause kidney problems.

g. Sensitivity to metals that built stents

h. Bleeding: Bleeding from the stent insertion site, from a tear in the artery where the stent was placed or from a puncture of the heart may occur after the procedure. If significant bleeding occurs, it is typically noted within the first 12 to 15 hours after stent placement. Signs of major bleeding include dizziness, lightheadedness and fainting. ${ }^{48,49}$

i. Stroke: stroke is one of the stenting complications that occur due to the removal of fat plaque. j. Heart attack: a heart attack is a big medical problem. During a heart attack, the blood that supplies heart oxygenation will cut off and heart muscle begins to die.

k. Palpitations and heart rhythm disturbances: Palpitations, the sensation of one's heart racing or skipping a beat are common after cardiac stent placement. This may occur due to improved blood flow reinvigorating injured areas of the heart. Palpitations might also signal serious heart rhythm disturbances that could be the result of a heart attack. A study reported in January 2013 in "The Scientific World Journal" found that about 83 percent of people who underwent cardiac stent placement had some type of temporary heart rhythm abnormality within the first 48 hours after the procedure. The significance of palpitations can be easily determined by an electrocardiogram. Depending on the cause of the palpitations, additional treatment may be needed.

One of the problems that can occur after PCI is too much tissue growth within the treated portion of the artery. This can cause the artery to become narrow or blocked again. When this happens, it's called restenosis. $^{50}$

Using drug-eluting stents can help prevent this problem. These stents are coated with medicine to stop excess tissue growth. Treating the tissue around the stent with radiation also can delay tissue growth. For this procedure, the doctor threads a wire through a catheter to the stent. The wire releases radiation and stops cells around the stent from growing and blocking the artery.

\section{Conclusion}

In recent years, consider to changes in people's life style due developing of industry and industrial life, the chance of developing vascular diseases has increased so researchers have developed methods to diagnose and cure these diseases that introduced in this article. The most common disorder in vascular system is Atherosclerosis, which plaques blocks vessels and decreases blood flow. Stents are useful device to overcome this inflammation. Stents have different generation. The last generation by using special polymers and drugs can overcome Atherosclerosis with lower risks. The last treatment is bypass surgery, which is not a desirable solution due to the complex process, complications and risks. Implantation of stents has some drawbacks such as recoil after expansion, but the technology continues to advance.

\section{Acknowledgements}

None.

\section{Conflict of interest}

The author declares no conflict of interest.

\section{References}

1. Lewis T. The blood vessels of the human skin. BrMedJ. 1926;2(3418):6162.

2. Chaudhuri S, Shankar C, Norman K, et al. Detection of blood vessels in retinal images using two-dimensional matched filters. IEEE Trans Med Imaging. 1989;8(3):263-269.

3. Diep QN, El Mabrouk M, Cohn JS, et al. Structure, endothelial function, cell growth, and inflammation in blood vessels of angiotensin II-infused rats: role of peroxisome proliferator-activated receptor- $\gamma$. Circulation. 2002;105(19):2296-2302. 
4. Intengan HD, Schiffrin EL. Schiffrin. Vascular remodeling in hypertension: roles of apoptosis, inflammation, and fibrosis. Hypertension. 2001;38(3 Pt 2):581-587.

5. Yancopoulos GD, Davis S, Gale NW, et al. Vascular-specific growth factors and blood vessel formation. Nature. 2000;407(6801):242-248.

6. Shirzadfar H, Ghaziasgar MS, Piri Z, et al. Heart beat rate monitoring using optical sensors. Int J Biosen Bioelectron. 2018;4(2):48-54;.

7. Shirzadfar H, Khanahmadi M, Mahlouji E. Wavelet Technique and Function for Noise Removal from ECG Signal. International Journal of Bioinformatics and Computational Biology. 2018;3(1):1-5].

8. Born GVR, Cross MJ. The aggregation of blood platelets. J Physiol. 1963;168(1):178-195

9. Virmani R, Burke AP, Farb A, et al. Pathology of the vulnerable plaque. $J$ Am Coll Cardiol. 2006;47(8 Suppl):C13-C18.

10. Andersen HR, Nielsen TT, Rasmussen K, et al. A comparison of coronary angioplasty with fibrinolytic therapy in acute myocardial infarction. $N$ Engl J Med. 2003;349(8):733-742.

11. Jia Y, Bailey ST, Hwang TS, et al. Quantitative optical coherence tomography angiography of vascular abnormalities in the living human eye. Proc Natl Acad Sci USA. 2015;112(18):E2395-E2402.

12. Tambe AA, Demany MA, Zimmerman HA, et al. Angina pectoris and slow flow velocity of dye in coronary arteries-a new angiographic finding. Am Heart J. 1972;84(1):66-71.

13. Shah A, Ashesh NB, Paul KD, et al. CRT-72 Radiation dose during coronary angiography: correlation to body mass index. JACC: Cardiovascular Interventions. 2018;6(2):S23.

14. Bluemke DA, Achenbach S, Budoff M, et al. Noninvasive coronary artery imaging: magnetic resonance angiography and multidetector computed tomography angiography: a scientific statement from the american heart association committee on cardiovascular imaging and intervention of the council on cardiovascular radiology and intervention, and the councils on clinical cardiology and cardiovascular disease in the young. Circulation. 2008;118(5):586-606.

15. Kip KE, Faxon DP, Detre KM, et al. Coronary angioplasty in diabetic patients: the national heart, lung, and blood institute percutaneous transluminal coronary angioplasty registry. Circulation. 1996;94(8):1818-1825.

16. Sokolov MY, Besh DI, Besh OM, et al. The influence of the manual thrombus aspiration on the short term effectiveness of the percutaneous revascularization in patients with coronary artery thrombosis. Wiad Lek. 2018;71(1 pt 2):140-143.

17. Shih TC, Lin YH, Ho YJ, et al. Hemodynamic analysis of vascular stenting treatment outcome: computational fluid dynamics method vs optical flow method. J Xray Sci Technol. 2012;20(4):469-481.

18. Chan YC, Cheng SW, Ting AC, et al. Primary stenting of femoropopliteal atherosclerotic lesions using new helical interwoven nitinol stents. $J$ Vasc Surg. 2014;59(2):384-391.

19. Nouralizadeh A, Sharifiaghdas F, Pakmanesh H, et al. Fluoroscopyfree ultrasonography-guided percutaneous nephrolithotomy in pediatric patients: a single-center experience. World J Urol. 2018;36(4):667-671.

20. Çimen HI, Halis F, Sağlam HS, et al. Flouroscopy-free technique is safe and feasible in retrograde intrarenal surgery for renal stones. Turk J Urol. 2017;43(3):309-312.

21. Byrne RA, Stone GW, Ormiston J, et al. Coronary balloon angioplasty, stents, and scaffolds. Lancet. 2017;390(10096):781-792.
22. Serruys PW, de Jaegere P, Kiemeneij F, et al. A comparison of balloonexpandable-stent implantation with balloon angioplasty in patients with coronary artery disease. Benestent Study Group. $N$ Engl J Med. 1994;331(8):489-495

23. Wiviott $\mathrm{SD}$, Braunwald $\mathrm{E}, \mathrm{McCabe} \mathrm{CH}$, et al. Intensive oral antiplatelet therapy for reduction of ischaemic events including stent thrombosis in patients with acute coronary syndromes treated with percutaneous coronary intervention and stenting in the TRITON-TIMI 38 trial: a subanalysis of a randomised trial. Lancet. 2008;371(9621):1353-1363.

24. Amarenco P, Labreuche J, Mazighi M. Lessons from carotid endarterectomy and stenting trials. Lancet. 2010;376( 9746):1028-1031.

25. Torpy JM, Lynm C, Glass RM. Percutaneous coronary intervention. JAMA. 2004;291(6):778-778.

26. Fischman DL, Leon MB, Baim DS, et al. A randomized comparison of coronary-stent placement and balloon angioplasty in the treatment of coronary artery disease. $N$ Engl J Med. 1994;331(8):496-501.

27. Brott TG, Hobson RW 2nd, Howard G, et al. Stenting versus endarterectomy for treatment of carotid-artery stenosis. $N$ Engl J Med. 2010;363(1):11-23.

28. What is a coronary angioplasty?

29. O'Donnell TFX, Deery SE, Schermerhorn ML, et al. The impact of perioperative ankle-brachial index and clinical status on outcomes following lower extremity bypass. Ann Vasc Surg. 2018.

30. Chang HW, Hwang HY, Seo JW, et al. Lower versus upper leg saphenous vein composite grafts based on the left internal thoracic artery: A randomized study. J Thorac Cardiovasc Surg. 2018.

31. Heart bypass surgery-series-Procedure, part 2.

32. Hou L, Yang Z, Wang Z, et al. NLRP3/ASC-mediated alveolar macrophage pyroptosis enhances HMGB1 secretion in acute lung injury induced by cardiopulmonary bypass. Lab Invest. 2018.

33. Colombo A, Stankovic G, Moses JW. Selection of coronary stents. J Am Coll Cardiol. 2002;40(6):1021-1033.

34. Demir AG, Barbara P, Qiang G, et al. Biodegradable magnesium coronary stents: material, design and fabrication. International Journal of Computer Integrated Manufacturing. 2014;27(10):936-945.

35. O'Brien B, Zafar H, Ibrahim A, et al. Coronary stent materials and coatings: a technology and performance update. Ann Biomed Eng. 2016;44(2):523-535.

36. Abizaid A, Costa JR Jr. New drug-eluting stents: an overview on biodegradable and polymer-free next-generation stent systems. Circ Cardiovasc Interv. 2010;3(4):384-393.

37. Witte F, Kaese V, Haferkamp $\mathrm{H}$, et al. In vivo corrosion of four magnesium alloys and the associated bone response. Biomaterials. 2005;26(17):3557-3563.

38. Polmear IJ. Magnesium alloys and applications. Materials science and technology. 1994;10(1):1-16.

39. Jeewandara TM, Wise SG, Ng MKC. Biocompatibility of coronary stents. Materials. 2014;7(2):769-786

40. Fortier A, Vikranth G, Reza AM. Review of biomechanical studies of arteries and their effect on stent performance. IJC Heart \& Vessels. 2014:4:12-18.

41. Palmerini T, Biondi-Zoccai G, Della Riva D, et al. Stent thrombosis with drug-eluting and bare-metal stents: evidence from a comprehensive network meta-analysis. Lancet. 2012;379(9824):1393-1402. 
42. Stettler C, Wandel S, Allemann S, et al. Outcomes associated with drugeluting and bare-metal stents: a collaborative network meta-analysis. Lancet. 2007;370(9591):937-948.

43. Scheinert D, Ulrich M, Scheinert S, et al. Comparison of sirolimuseluting vs. bare-metal stents for the treatment of infrapopliteal obstructions. EuroIntervention. 2006;2(2):169-174.

44. Costa MA, Sabate M, Kay IP, et al. Three-dimensional intravascular ultrasonic volumetric quantification of stent recoil and neointimal formation of two new generation tubular stents. Am J Cardiol. 2000;85(2):135-139.

45. Tada T, Byrne RA, Simunovic I, et al. Risk of stent thrombosis among bare-metal stents, first-generation drug-eluting stents, and secondgeneration drug-eluting stents: results from a registry of 18,334 patients JACC Cardiovasc Interv. 2013;6(12):1267-1274.

46. Alfonso F, Fernandez C. Second-generation drug-eluting stents: moving the field forward. J Am Coll Cardiol. 2011;58(1):26-29.
47. Sajnani N, Bogart DB. Retroperitoneal hemorrhage as a complication of percutaneous intervention: report of 2 cases and review of the literature. Open Cardiovasc Med J. 2013;7:16-22.

48. Iqbal J, Gunn J, Serruys PW. Coronary stents: historical development, current status and future directions. Br Med Bull. 2013;106:193-211.

49. Herz: Chest Pain After Coronary Interventional Procedures: Incidence and Pathophysiology Centers for Disease Control and Prevention: Leading Causes of Death National Heart, Lung and Blood Institute: What Is a Stent.

50. Levine GN, Bates ER, Blankenship JC, et al. 2011 ACCF/AHA/SCAI guideline for percutaneous coronary intervention: a report of the american college of cardiology foundation/american heart association task force on practice guidelines and the society for cardiovascular angiography and interventions. Circulation. 2011;124(23):e574-651. 